\title{
Signals of recent tropical radiations in Cunoniaceae, an iconic family for understanding Southern Hemisphere biogeography
}

\author{
Ricardo A. Segovia ${ }^{1,2}$, Andy R. Griffiths ${ }^{1}$, Diego Arenas ${ }^{3}$, \\ A. A. Piyali Dias ${ }^{1,4}$, Kyle G. Dexter ${ }^{1,4}$ \\ 1 School of GeoSciences, University of Edinburgh, United Kingdom. \\ 2 Instituto de Ecología y Biodiversidad (www.ieb-chile.cl), Santiago, \\ Chile. \\ 3 School of Computer Science, University of St Andrews, United \\ Kingdom. \\ 4 Royal Botanic Garden Edinburgh, United Kingdom. \\ * ricardo.segovia@ed.ac.uk
}

\begin{abstract}
Extratropical angiosperm diversity is thought to have arisen from lineages that originated in the more diverse tropics, but studies of dispersal between tropical and extratropical environments and their consequences for diversification are rare. In order to understand the evolutionary effects of shifts between the tropics and extratropics, defined here as areas that $d o$ versus do not regularly experience freezing temperatures, we studied the biogeographic history and associated diversification patterns of Cunoniaceae. We mapped the distribution of all species in the family and combined this with a newly constructed phylogeny for the family. The family shows a long evolutionary association with both tropical and extratropical environments, the tropics house considerably greater species richness of Cunoniaceae. Indeed, both tropical and extratropical environments appear to have had a similar number of lineages until $12 \mathrm{Ma}$, after which time the number of lineages in tropical areas increased at a faster rate. In addition, community phylogenetic approaches show that tropical regions have markedly less phylogenetic diversity than expected given their species richness, which is further suggestive of recent species radiations in tropical areas. The Cunoniaceae show an atypical pattern for angiosperms of frequent shifts between tropical and extratropical environments, but despite this, shows a more conventional pattern of higher, although recent, diversification rates in the tropics. Our results support the idea that high angiosperm species richness in the tropics may result from the tropics acting as a cradle of recent angiosperm diversification.
\end{abstract}




\section{Introduction}

The widely observed pattern of decreasing plant diversity from low 2 to high latitudes is accompanied by conspicuous phylogenetic, taxo- 3 nomic and functional turnover $(e . g \cdot[1,2])$. Within angiosperms, the 4 evolutionary dispersal of tropical, low latitude lineages into extratrop- $\quad 5$ ical, high latitudes is relatively rare $[3,4]$. When such dispersal does 6 occur, it is enabled by the evolution of functional traits conveying $\quad 7$ tolerance of freezing environments, such as herbaceous habit, decid- 8 uousness and hydraulic adjustments [5]. Similarly, the movement 9 of temperate-adapted lineages back into truly tropical climates also $\quad 10$ seems rare [6]. As such, the modern distribution of angiosperm tree 11 lineages across the Americas is strongly associated with the pres- 12 ence or absence of freezing temperatures [7]. Although the origin of 13 extratropical plant diversity may be associated with the evolution $\quad 14$ of tolerance to freezing conditions [8], the persistent restriction of ${ }_{15}$ tropical lineages to tropical environments and extratropical lineages 16 to extratropical environments [9] limits opportunities to study the 17 evolutionary processes associated with shifts between tropical and 18 extratropical environments (e. g. [10]). The angiosperm family 19 Cunoniaceae offers one such rare opportunity to study the evolu- 20 tionary history of a clade in the context of tropical-extratropical ${ }_{21}^{21}$ environmental shifts.

Cunoniaceae (Oxalidales) is an iconic Southern Hemisphere 23 family, containing 28 genera and c. 300 species of trees and shrubs, 24 inhabiting both tropical and extratropical environments [11]. The 25 cross-continental distribution of genera such as Cunonia, Weinman- 26 nia, Eucryphia or Caldcluvia reflects a deep history in Southern 27 Hemisphere landmasses. Indeed, the major diversification of the 28 Cunoniaceae is thought to have occurred in the Gondwanan region 29 [12]. However, whether tropical ( $i$. e. frost-free environments) 30 
and/or extratropical (i. e. freezing environments) environments are 31 associated with the initial and later diversification is currently un- 32 clear. Similarly, a tropical or extratropical origin and diversification 33 of Weinmannia, the most speciose genus in the family (comprising 34 $\sim 44 \%$ of species), has yet to be clarified [13].

Biogeographic studies on the distribution of the Southern 36 Hemisphere biota have traditionally centered on two main processes: 37 vicariance associated with the Gondwanan breakup $[14,15,16,17, \quad 38$ 18], and long-distance dispersal through wind and ocean currents 39 $[19,20,21]$. Yet, recently documented evidence for environmental 40 constraints on the evolution and dispersal of lineages [22, 23], under- 41 lines the need to develop an alternative perspective in the study of 42 biogeography, based on the principle of phylogenetic niche or biome 43 conservatism. Moreover, Southern Hemisphere trends suggest that ${ }_{44}$ the environmental divide between the tropics and extratropics may 45 be a key determinant of the distribution of modern-day diversity. For 46 example, phylogenetic analyses for lineages in the Southern Hemi- 47 sphere show that intercontinental dispersal events are more frequent 48 than environmental shifts, even between neighboring tropical and ex- 49 tratropical biomes [24]. Furthermore, the fossil record shows a lower 50 than expected interchange of plant lineages between the Neotropics 51 and the extratropics of southern South America across the whole 52 Cenozoic [25].

Hypotheses regarding evolutionary biogeography can be $\quad 54$ directly explored using phylogenetic approaches. For example, an- 55 cestral state reconstructions can track the evolutionary history of 56 lineage characteristics, such as climatic niches, across a phylogenetic $\quad 57$ tree $[26,27]$. More recently, biogeographic insights have been pro- 58 vided by analyzing variation in community phylogenetic structure $\quad 59$ across biogeographic regions, biomes and environmental gradients 60 (e. g. $[28,29,30,31])$. Standardized phylogenetic diversity (sPD), ${ }_{61}$ 
that is phylogenetic diversity $(\mathrm{PD})$ given variation in species richness $\quad 62$

(SR), can be used as a metric of community phylogenetic structure 63

[32]. Areas with significantly lower PD than expected, given SR, are 64

composed of closely related species. Such phylogenetic clustering of 65

related species in an assemblage can result from rapid speciation, se- 66

lective extinction of older lineages, or reduced interchange of lineages $\quad 67$

among communities or geographic regions [33, 34]. In contrast, areas 68

with significantly greater PD than expected, given SR, are composed $\quad 69$

of distantly related species. Such phylogenetic overdispersion can 70

result from lower diversification rates in recent time than deeper time, 71

higher recent extinction, or frequent interchange of distantly related 72

$\begin{array}{ll}\text { lineages among regions }[33,34] . & 73\end{array}$

In this study, we combine a newly derived phylogeny for 74

Cunoniaceae with global occurrence and climatic data to gain insight $\quad 75$

into how dispersal events across the tropical-extratropical divide 76 shaped the evolutionary biogeography of the family. We firstly re- 77 construct the ancestral tropical or extratropical affiliation of all $28 \quad 78$ described genera within Cunoniaceae. In addition, we make a com- 79 parison of phylogenetic structure, phylogenetic signal, and variation $\quad 80$ in lineage diversity through time between tropical, non-freezing envi- 81 ronments and extratropical, freezing environments. The evolutionary 82 origins of angiosperms in general is thought to have occurred in 83 tropical, non-freezing environments, with only a subset of lineages 84 evolving tolerance to freezing conditions and making the shift to 85 extratropical environments [8]. If the Cunoniaceae follow this gen- 86 eral tropical-origin trend, we anticipate a phylogenetically clustered $\quad 87$ pattern in assemblages from extratropical environments and/or a 88 phylogenetic signal for extratropicality ( $i$. e. extratropical species 89 will be more closely related than expected by chance). Alternatively, 90 if tropical distribution is an evolutionary novelty within the Cunon- 91 iaceae, with tropical lineages deriving from extratropical lineages, 92 
we expect phylogenetic clustering in assemblages from tropical envi- 93 ronments, and/or a phylogenetic signal for tropicality. Finally, we 94 evaluate whether there is phylogenetic structure behind the variation 95 in species richness of Cunoniaceae across climatic space. In envi- 96 ronments where Cunoniaceae has experienced a recent and rapid $\quad 97$ species radiation, we expect assemblages to have both high species $\quad 98$ richness and display phylogenetic clustering ( $i$. e. significantly low 99 SPD values). In contrast, in environments where the diversification 100 of Cunoniaceae has been comparatively slow, we expect random SPD 101 values centred on zero, or a pattern of phylogenetic overdispersion 102 (i. e. significantly high sPD values), if there are many old, yet 103 undiversified lineages.

Cunoniaceae occurrence data were downloaded from GBIF on August 107 28th, 2019 using the 'occ_search' function in the 'rgbif' package [35] 108 for R [36]. First, we excluded duplicate and incomplete occurrences. 109 Then, we used the function 'clean_coordinates' in the R package 110 'CoordinateCleaner' [37] to filter the occurrence data, excluding col- ${ }_{111}$ lections from capitals, centroids of countries, GBIF headquarters, 112 natural history institutions, and collections occurring in the sea. We 113 also identified records considered as outliers in the environmental 114 space the given species occupies. Environmental outlier detection 115 was performed by running a reverse-jackknife method on six climatic 116 variables: mean annual temperature, maximum temperature of the ${ }_{117}$ warmest month, minimum temperature of the coldest month, mean 118 annual precipitation, precipitation of the wettest month, and precipi- 119 tation of the driest month, extracted from WorldClim [38]. These 120 
variables were selected to reflect the climatic averages and boundaries 121 of species' ranges. The method, which has precedence (e. g. $[39,40], 122$ consists of identifying outlier samples ( $i$. e. occurrences) for each 123 climatic variable based on a critical threshold derived from the mean, 124 standard deviation, and range of the whole set of samples for a given $\quad 125$ species (i. e. all occurrence points). Potential outlier occurrences 126 were determined as those where values for at least 2 of the $6(>20 \%) \quad{ }_{127}$ environmental variables were identified as statistical outliers. If there ${ }_{128}$ was not enough information to compute this analysis (here, less than 129 10 occurrences for a given species), then the environmental outlier 130 analysis was not performed. The final GBIF distribution dataset 131 contained 54,717 records, with an average of 181 records per species, 132 a minimum of 1 record (for $19 \mathrm{spp}$ ) and a maximum of 26,432 records 133 (for Weinmannia racemosa).

Given the climatic [41] and evolutionary [7] importance of freezing 136 environments as a division between tropics and extratropics, we classi- 137 fied the species in our dataset as Tropical, Extratropical or Generalist 138 based on the proportion of occurrences subject to regularly freezing 139 temperatures. We defined the tropics as those environments not 140 subject to freezing temperatures in a normal year. The extratropics 141 were conversely defined as those environments subjected to regular 142 freezing temperatures. Using a global climatic layer for cumulative 143 frost days over 117 years between 1901 and 2018 (Climatic Research 144 Unit (CRU), [42]), we defined 117 total days of freezing ( $i$. e. one 145 day of frost per year on average) as the threshold for 'regularly ex- 146 periencing' freezing temperatures versus not. Some regions can sum 147 117 days with freezing temperatures in a non-regular way, such as 148 areas subject to periodic polar outbreaks [43]. However, we consider 149 $\begin{array}{ll}\text { our approach to provide an objective threshold for environments } & 150\end{array}$ 

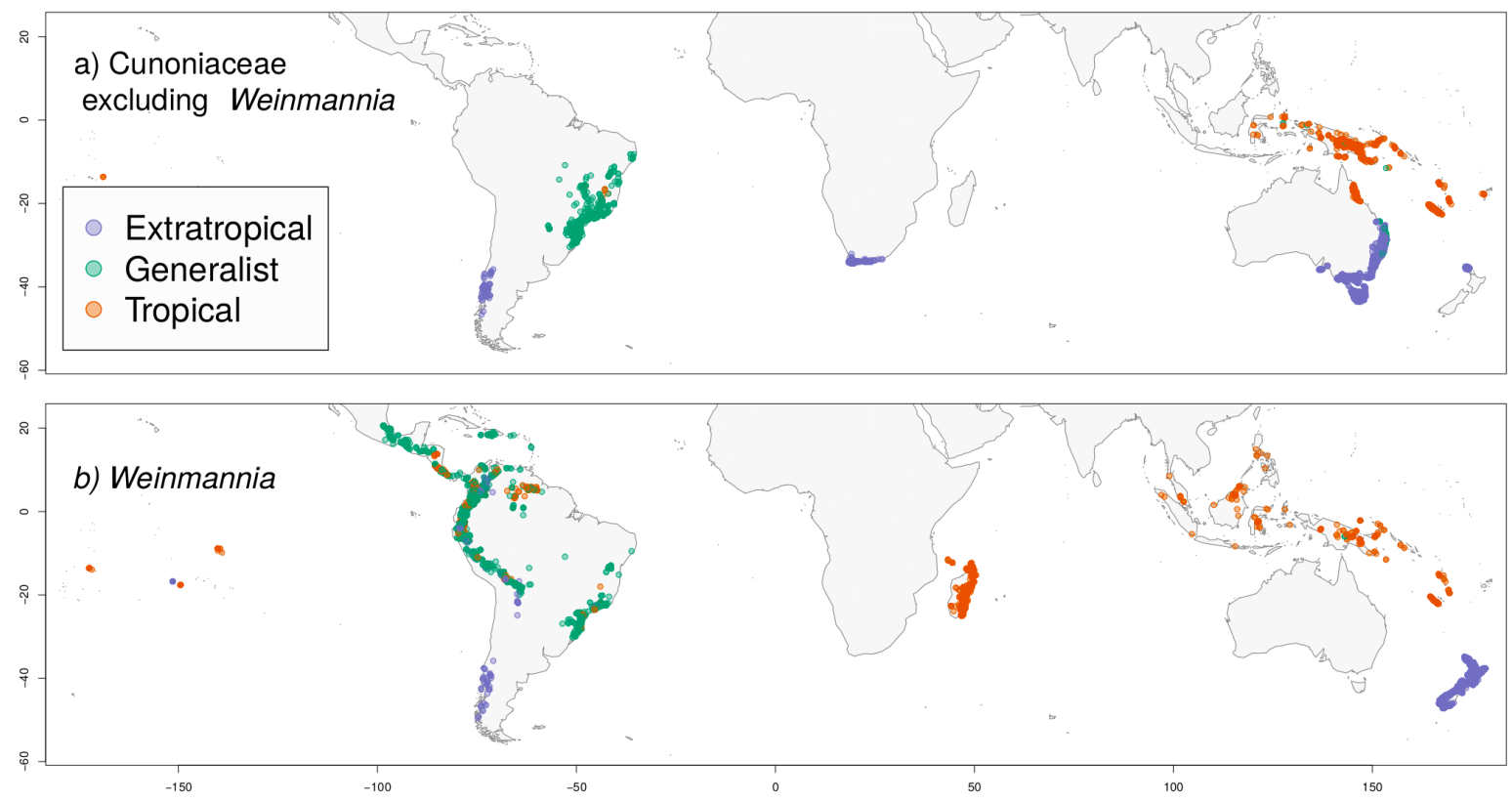

Figure 1. Distribution of the family Cunoniaceae. a) Distribution of the family Cunoniaceae excluding Weinmannia (169 non-Weinmannia spp) and b) Distribution of Weinmannia (133 spp). Purple dots represent occurrences of species classified as Extratropical. Orange dots represent occurrences of species classified as Tropical. Green dots represent occurrences of species classified as Generalist.

where freezing is relevant. Based on these freezing data we defined Extratropical species as those with more than $75 \%$ of their occurrences

In order to build the phylogeny, sequence data from NCBI were 165 gathered using PyPHLAWD, with a clustering method [44]. The 6166 best clusters (trnL (52 spp), phyC (45 spp), rbcL (42 spp), ncpGS 167 (38 spp), GapC (20 spp), matK (15 spp)) were aligned individually in ${ }_{168}$ MAFFT [45]. The total matrix included 82 species from 22 genera, 169 
and 7,179 bps. A Maximum Likelihood tree was estimated using 170 RaxML v8.2.12 [46], with a separate GTR $+\Gamma$ model for each 171 gene. This resulting phylogeny was then temporally calibrated using 172 treePL [47], with the crown age for the family taken from the its 173 first occurrence in the fossil record: Maastrichtian [48]. Thus, we set 174 crown age to a maximum of $70 \mathrm{Myr}$ and a minimum of $66 \mathrm{Myr} . \quad 175$

We manually added genera to the phylogeny for which no 176 DNA sequences were available. Exact placement of manual additions 177 was based on consultation of morphological and molecular phylogenies $\quad 178$ for Cunoniaceae and sections thereof (Table 1). Added genera were 179 placed halfway along the branch leading to their sister genus or clade 180 in the phylogeny. Branch lengths leading to added genera were set 181 such that the tree remained ultrametric. Then, we randomly added 182 species without sequence data into their respective genus.

Table 1 Genera added to the molecular phylogeny in this study, because they were present in 184 the distributional dataset, but lacked DNA sequence data to be placed in molecular phylogeny we generated. The position is represented in relation to the most closely related genera following the cited reference.

\begin{tabular}{l|l|l}
\hline Genus & Phylogenetic position & Reference \\
\hline Ackama & (Ackama, Spiraeopsis $)$ & {$[13]$} \\
\hline Acrophyllum & (Acrophyllum, Eucryphia) & {$[49]$} \\
\hline Acsmithia & (Acsmithia, Spiraeanthemum) & {$[13]$} \\
\hline Aistopetalum & (Aisotopetalum, Hooglandia) ${ }^{*}$ weakly supported & {$[49]$} \\
\hline Bauera & (Bauera, Ceratopetalum) & {$[49]$} \\
\hline Opocunonia & (Opocunonia (Ackama, Spiraeopsis) $)$ & {$[13]$} \\
\hline
\end{tabular}

To assess tropical or extratropical associations at deeper evolutionary 190 levels within our phylogeny, we reconstructed ancestral states accord- 191 ing to our ecological classification for species. These analyses were 192 conducted at the genus-level because the relationships of many species 193 
within genera are uncertain, particularly for un-sequenced species, 194 while we have greater confidence in the relationships amongst genera 195 (the majority of nodes in the phylogeny deeper than the genus-level 196 have maximum likelihood bootstrap support values $\geq 70$ ). Genera 197 were classified as Tropical if all the species within a given genus 198 were classified as Tropical (10 genera). Those genera with all their 199 species classified as Extratropical were classified as Extratropical ( 7200 genera). Otherwise, genera were considered Generalist (11 genera). 201 Prior to ancestral state reconstruction, we evaluated support for an 202 equal or unequal transition rate model (for transitions among the 203 three states), with the equal transition rate model best supported. 204 Ancestral states were then estimated using a maximum likelihood 205 with an equal rates model [27]. In order to illustrate the distribution 206 of genera across environmental space, we show the frequency of classi- 207 fied species occurrences across gradients of mean annual temperature 208 (MAT) and mean annual precipitation (MAP).

We estimated taxonomic and phylogenetic indices of diver- 210 sity for the groups of species classified as "Tropical", "Extratropical" ${ }_{211}$ or "Generalists". For phylogenetic indices of diversity, we estimated 212 Phylogenetic Diversity (PD, [50]) and Time Integrated Lineage Diver- 213 sity (TILD, [51]). As the number of lineages monotonically increase 214 towards the present, PD is weighted heavily towards lineage diversity 215 in recent evolutionary time compared to deeper evolutionary time. 216 TILD is estimated from a log-transformed number of lineages at each 217 point in time, which down-weights the influence of recent lineage 218 diversity and gives greater weight to deep-time lineage diversity. The 219 indices therefore can be considered complementary when making com- 220 parisons of phylodiversity across groups of species or regions [51]. We ${ }^{221}$ also compared values of standardized Phylogenetic Diversity (sPD) 222 to evaluate the phylogenetic structure of the tropical, extratropical 223 and generalist assemblages as a whole. We investigated phylogenetic 224 
signal for tropical or extratropical affinity of species using the $D \quad 225$ index [52] for binary traits (with 1,000 permutations in each case to 226 test for significance). Lastly, in order to illustrate variation in lineage 227 diversity over time, we also constructed lineage through time (LTT) 228 plots for a phylogeny comprising all species in tropical regions versus 229 a phylogeny comprising all species occurring in extratropical regions. 230

In order to evaluate the relationship between species rich- 231 ness, phylogenetic structure and environmental conditions, we arrayed 232 our distributional dataset across an environmental space defined by 233 Mean Annual Temperature (MAT) and Mean Annual Precipitation 234 (MAP). Each species occurrence was assigned to a 'bin' coordinated 235 by evenly partitioned vectors of MAT and MAP (60 and 40 bins for 236 each vector, respectively). Thus, we created 2,400 potential bins of ${ }_{237}$ species in the environmental space. Many combinations of MAP and 238 MAT do not have any Cunoniaceae species, so not all bins are filled. 239 For each of the bins with species, we estimated species richness and 240 calculated standardized Phylogenetic Diversity (sPD). We efficiently 241 derived the SPD index for so many bins by calculating the first two 242 moments of the null expectation for Phylogenetic Diversity (PD), 243 and then using the moments to calculate a standardized effect size of 244 PD for each bin, which we equate with sPD [53]. Considering the 245 preponderance of Weinmannia in the family (133 spp out of $302 \mathrm{spp} 246$ in our dataset), we estimated these indices on datasets both including 247 and excluding this genus.

We assessed the significance of phylogenetic clustering 249 or overdispersion for species found in each environmental bin by 250 comparing the observed SPD values to the distribution of these 251 values under a null model scenario. We did this because of concerns 252 around artefactual correlations between species richness and SPD 253 values [54]. To develop the null expectation for sPD values, we 254 maintained the total species richness of each bin while randomly 255 
assigning species identities by sampling without replacement from 256 the pool of species present in the community matrix. We created 1,000 257 null assemblages per environmental bin. This null model assumes 258 that all species present in our dataset are equally able to colonize 259 any environmental bin. Bins were considered to be significantly 260 phylogenetically overdispersed or clustered if they occurred in the 261 lowest or highest $2.5 \%$ of the distribution of values from the null 262 assemblages ( $i$. e., a two-tailed test with $\alpha=0.05$ ).

All analyses were conducted in the R Statistical En- 264 vironment [36] using functions in the "geiger" [55], "ape" [56], 265 "caper" [57], "Picante" [58], "biogeo" [59] and "PhyloMeasures" 266 [53] packages. A repository with the codes can be found in 267 https://github.com/ricardosegovia/Cunoniaceae.

Across taxa with enough data to classify, 47 species from 270 16 genera were classified as Extratropical, 215 species from 21 genera 271 were classified as Tropical and 40 species from five genera were clas- 272 sified as Generalists (Table 2). Eight genera included both Tropical 273 and Extratropical species, while an additional three also included 274 Generalist species. Thus eleven genera in total are classified as gen- 275 eralist. Most of the Generalist species are from the Weinmannia 276 genus (33 of 40) and are found in the Andes (Fig. 1), which repre- 277 sent a mosaic of regularly freezing and non-freezing environments. 278 The other genera containing generalist species are Bauera (1 sp), 279 Schizoemeria (1 sp), Spiraeanthemum (2 spp) and Lamanonia (3 280 spp). Tropical species are largely distributed in northern Australia, 281 the Malay Archipelago (plus New Guinea) and Madagascar (Fig. 282 1). In contrast, Extratropical species are associated with southern 283 Australia, New Zealand, South Africa and southern South America 284 
bioRxiv preprint doi: https://doi.org/10.1101/2020.01.23.916817; this version posted January 24, 2020. The copyright holder for this preprint (which was not certified by peer review) is the author/funder, who has granted bioRxiv a license to display the preprint in perpetuity. It is made available under aCC-BY-ND 4.0 International license.

(Fig. 1). Interestingly, Weinmannia is absent in Australia and is the 285 only representative of the family in Madagascar (Fig. 1).

Ancestral state reconstructions cannot resolve a tropical or $\quad 287$ extratropical origin for the oldest nodes in the Cunoniaceae family 288 tree. For example, the sister clade to the remainder of the family, 289 composed of Spiraeanthemum and Acsmithia, has a high association 290 with tropical environments, while the next sister clade of the 291

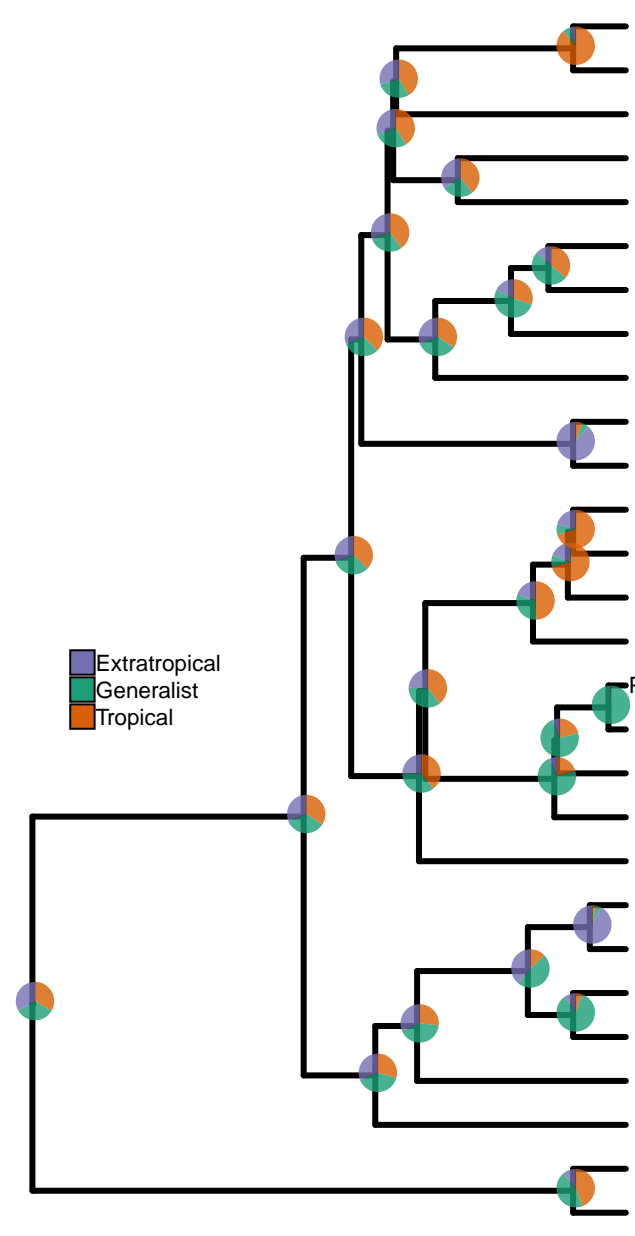

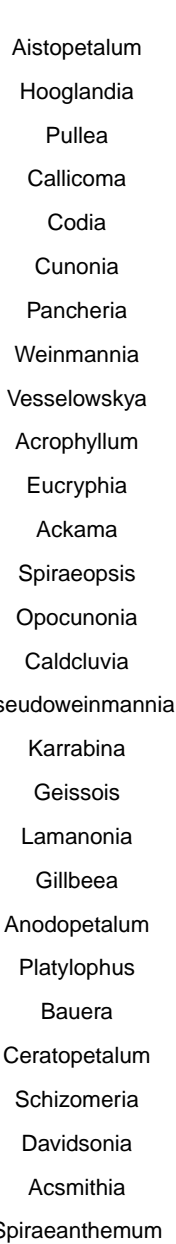

5
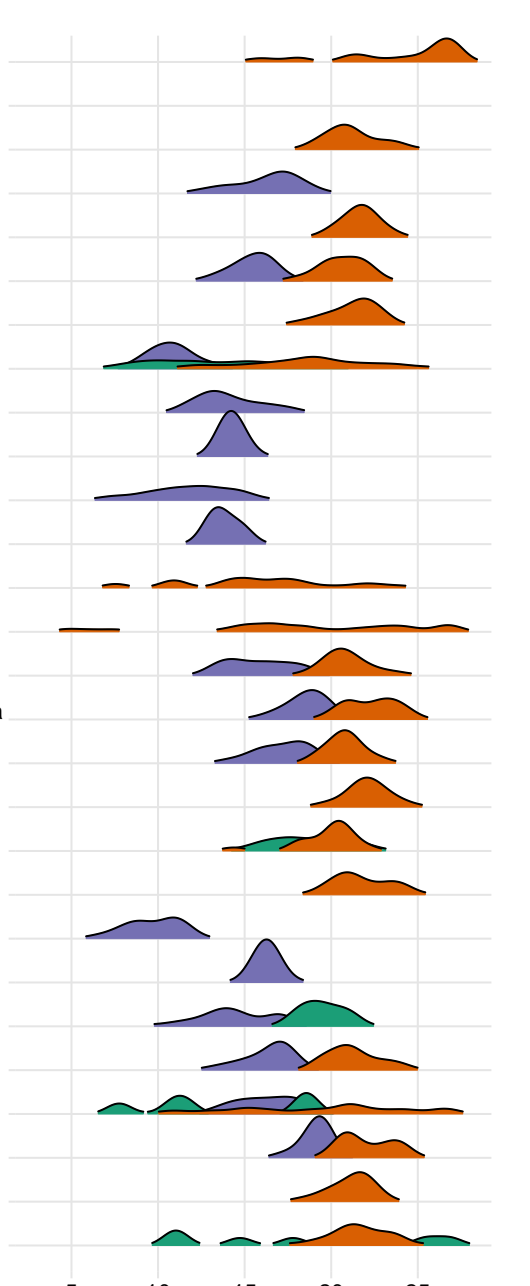

10

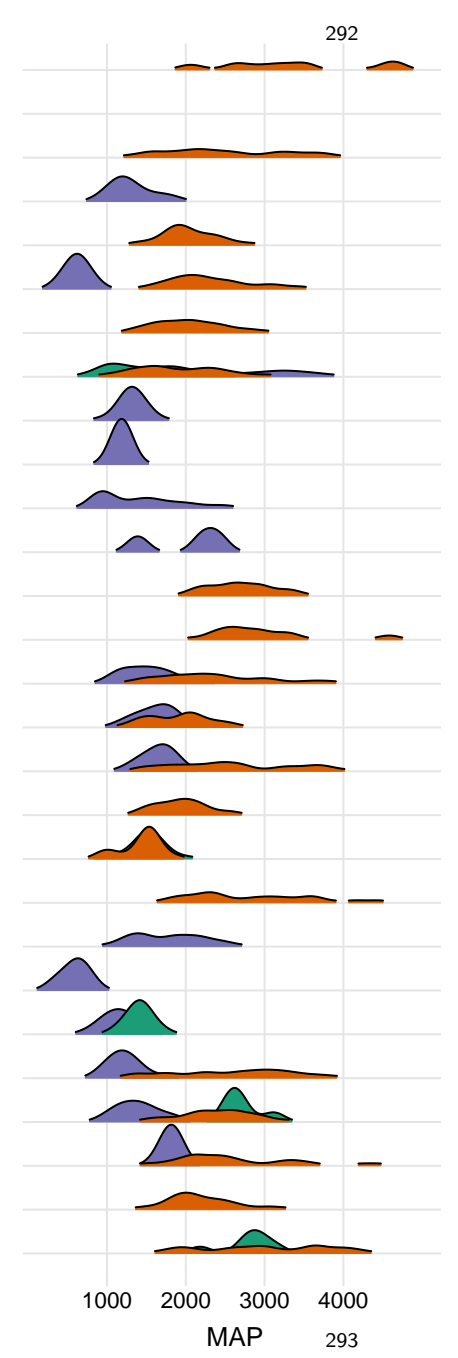

Figure 2. Genus-level phylogeny with ancestral state reconstruction for tropical or extratropical 294 environments. The environmental distributions of Cunoniaceae genera across gradients of Mean 295 Annual Temperature (MAT) and Mean Annual Precipitation (MAP) are also shown. Colours in 296 the right-hand panel illustrate the respective distributions for species within the genus classified as 297 Tropical, Extratropical or Generalist. 
remainder of the family, composed by Davidsonia, Schizoemeria, 299 Ceratopetalum, Bauera, Platylopus, and Anodopetalum, tends more 300 towards an association with extratropical environments (Fig. 2). 301 In more recently derived clades, ancestral state probabilities show 302 environmental associations that have moved in both tropical-to- 303 extratropical, and extratropical-to-tropical directions (Fig. 2). The 304 high number of genera (11 of 28) with species in both the Tropics and 305 Extratropics further points to the high number of evolutionary shifts 306 between tropical and extratropical environments. Tropical species 307 tend to be distributed in areas with $\geq 20^{\circ} \mathrm{C}$ mean annual temperature 308 (MAT), although species from Spiraeopsis and Opocunonia can occur 309 at lower MAT (Fig. 2). On the other hand, Extratropical species are 310 distributed in environments with lower precipitation, especially the 311 African genera Cunonia and Platylophus (Fig. 2).

The lineage through time (LTT) plot shows that both 313 tropical and extratropical regions contain similar diversity in terms of 314 number of older lineages ( 47 Ma) (Fig. 3). The tropical assemblage 315

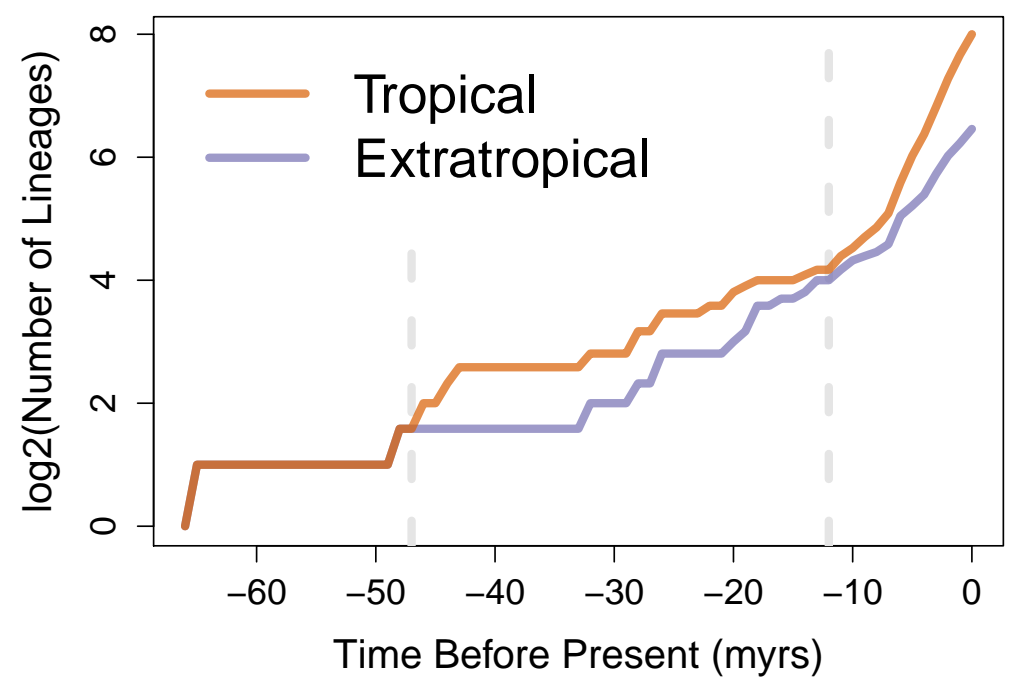

Figure 3. Number of Lineages Through Time (LTT) for Tropical and Extratropical species 317 assemblages. Lineages from Generalist species have been included in both Tropical and Extratropical 318 assemblages. Vertical lines indicate evolutionary depths at which Extratropical and Tropical 319 Assemblages had a similar numbers of lineages. 
contains greater lineage diversity for intermediate evolutionary ages 321 (between $\sim 47$ and $\sim 12 \mathrm{Myr}$ old). Within the last $12 \mathrm{Myr}$, the 322 number of lineages in tropical regions has increased much faster than 323 in extratropical regions (note log-scale of y-axis in Fig. 3), which is 324 epitomized by the fact that at present, tropical regions have nearly 325 three times as many species as extratropical regions (245 versus 87326 species, when including generalists in both).

Overall phylogenetic diversity (PD) is markedly higher for 328 the assemblage of species in tropical environments (non-freezing) 329 than in extratropical environments (freezing; Table 2). The TILD 330 measure of deeper-time lineage diversity is also higher in the tropics, 331 but the difference between tropics and extratropics for that measure 332 is less pronounced. In contrast, sPD is lower, or more negative, for 333 the tropical assemblage than the extratropical assemblage of species 334 (Table 2), indicating greater phylogenetic clustering in the tropics. 335 While the pattern of overall tropical clustering is stronger when 336 excluding Weinmannia, the trend of overdispersion in the Generalist 337 group disappears when Weinmannia is excluded (Table 2). As such, 338 the generalist distribution of the very speciose Weinmannia may be 339 strongly affecting phylodiversity indices and obscuring the patterns of 340 phylogenetic structure observed across the remainder of Cunoniaceae. 341 Complimentary to the above analyses, we find phylogenetic signal, 342 significantly different from random expectations (which would give 343 a $D$ value of 1$)$, for both tropical species $(D=0.5, p<0.001)$ and 344 extratropical species $(\mathrm{D}=0.64, p<0.001)$. A lower $D$ value in the 345 Tropics reinforces that tropical species are more closely related to 346 each other on average than extratropical species (as values closer to 347 zero indicate greater phylogenetic signal; Table 2).

The distribution of species richness (SR) in environmental 349 bins displays two distinguishable areas of high values (Fig. 4a, d). 350 One area of high species richness is distributed towards relatively 351 
Table 2 Taxonomic and phylogenetic diversity indices for Tropical, Extratropical and Generalists 352 species assemblages. Some genera contain Tropical and/or Extratropical and/or Generalist species, 353 and are included under more than one column for genus richness totals, as pertinent. The indices 354 are estimated for the whole Cunoniaceae family and for Cunoniaceae excluding Weinmannia. For 355 standardized phylogenetic diversity (sPD), asterisks represent the P-value (quantile) of observed PD 356 vs. null communities produced by 1,000 randomizations. For $D$, asterisks represent the probability 357 of estimated $D$ resulting under no phylogenetic signal. ${ }^{*}$ if $\mathrm{p}<0.1, * *$ if $\mathrm{p}<0.05,{ }^{* * *}$ if $\mathrm{p}<0.001$.

\begin{tabular}{|c|c|c|c|}
\hline & Extratropical & Generalists & Tropical \\
\hline \multicolumn{4}{|l|}{ Cunoniaceae (all genera) } \\
\hline Species Richness & 47 & 40 & 215 \\
\hline Genera Richness & 16 & 5 & 21 \\
\hline Phylogenetic Diversity (Myr) & 509.48 & 364.21 & 1195.53 \\
\hline TILD (Myr) & 88.09 & 90.07 & 135.05 \\
\hline Standardized Phylogenetic Diversity (sPD) & -0.72 & $-2.51^{* *}$ & $-2.22^{* *}$ \\
\hline$D$ index & $0.63^{* * *}$ & $0.68^{* * *}$ & $0.50^{* * *}$ \\
\hline \multicolumn{4}{|l|}{ Cunoniaceae excluding Weinmannia } \\
\hline Species Richness & 26 & 7 & 136 \\
\hline Genera Richness & 15 & 4 & 20 \\
\hline Phylogenetic Diversity (Myr) & 421.97 & 226.40 & 974.04 \\
\hline TILD (Myr) & 85.11 & 76.89 & 132.75 \\
\hline Standardized Phylogenetic Diversity (sPD) & -0.70 & 0.46 & $-4.42^{* * *}$ \\
\hline$D$ index & $0.24^{* * *}$ & $0.55^{* * *}$ & $0.30^{* * *}$ \\
\hline
\end{tabular}

high Mean Annual Temperature (MAT) and high Mean Annual 360 Precipitation (Fig 4a, d), while a further area of high richness is 361 distributed towards lower MAT and lower MAP (Fig 4a, d). When 362 excluding Weinmannia, only the former peak of species richness (high 363 MAT and MAP) remains (Fig. 4d). 364 A negative correlation $(\mathrm{r}=-0.313, \mathrm{p}<0.0001)$ was found 365 between SR and standardized Phylogenetic Diversity (sPD) when 366 considering all Cunoniaceae species (Fig. 4a b) and when excluding 367 Weinmannia $(\mathrm{r}=-0.401, \mathrm{p}<0.001)$ (Fig. $4 \mathrm{~d} \mathrm{e})$. The correlation 368 between SR and sPD suggests that the most speciose assemblages are 369 also the least phylogenetically diverse assemblages. Our null model 370 analysis (Fig. 4c f) allows us to rule out a potentially artefactual 371 relationship between $\mathrm{SR}$ and $\mathrm{SPD}$, as cautioned by [54], at least for 372 the extremes of species richness values. When considering the whole 373 

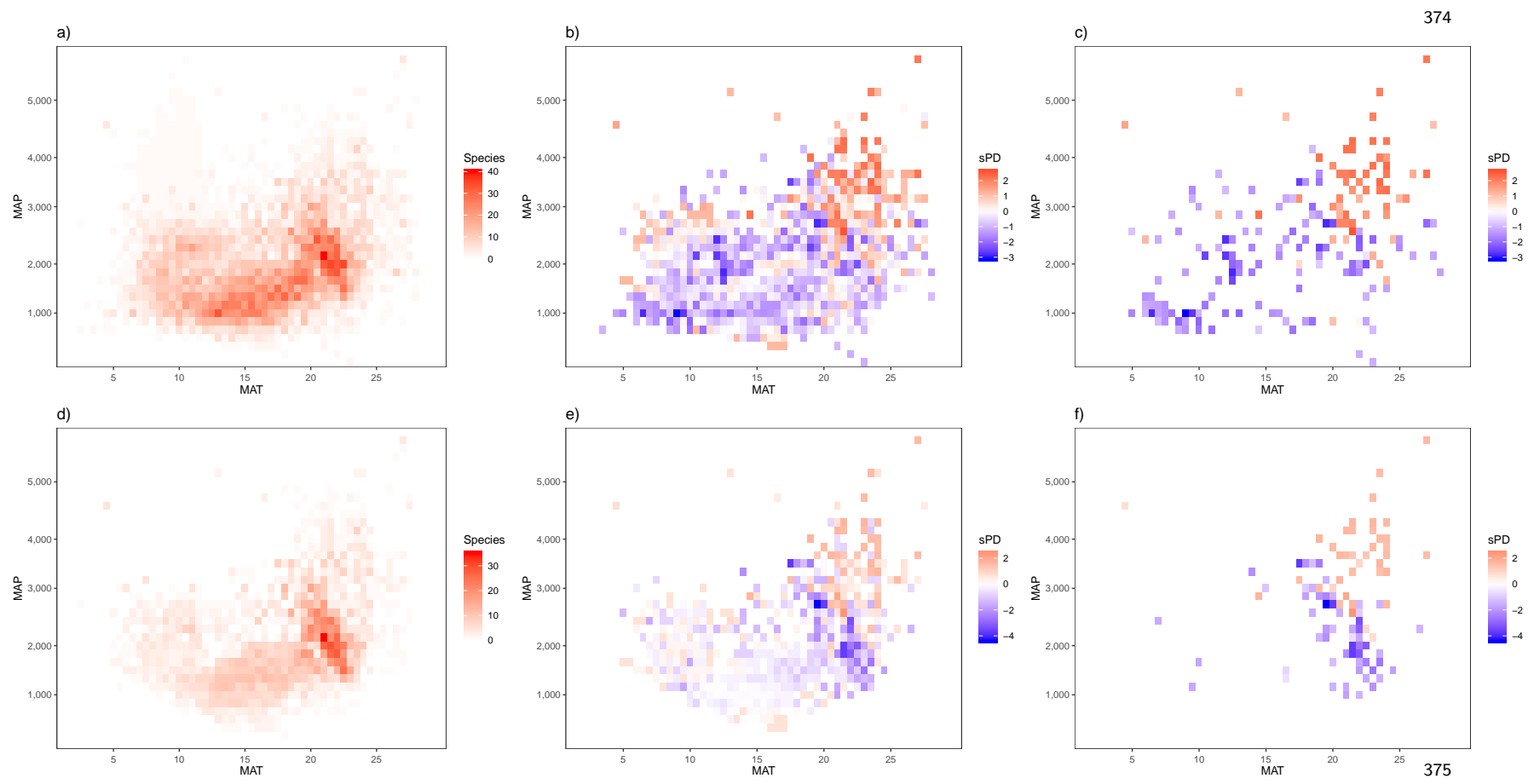

Figure 4. Species Richness (SR) and Standardized Phylogenetic Diversity (sPD) across variation 376 in Mean Annual Temperature (MAT) and Mean Annual Precipitation (MAP). Plots a), b) and c) 377 consider the whole family Cunoniaceae, and d), e) and f) consider the Cunoniaceae family excluding 378 Weinmannia. Panels c) and f) show the values of sPD that reflect significant phylogenetic clustering 379 (negative values) or overdispersion (positive values), based on a null model analysis (see main text 380 for details).

family (Fig 4a c), we see that the most phylogenetically overdispersed 382 assemblages can be found within the hottest and wettest environ- 383 ments, while a number of phylogenetically clustered assemblages 384 are found towards cooler and drier environments (in both tropical 385 and extratropical portions of climatic space). When Weinmannia is 386 excluded from analyses (Fig. 4e f), those environmental bins that 387 show significant phylogenetic clustering are in relatively warm and 388 wet ( $i$. e. tropical) environments compared to the environmental 389 range of the genus as a whole (Fig. 2). Meanwhile, there are few 390 environmental bins that show significant phylogenetic overdispersion 391 once Weinmannia is excluded from analyses. Weinmannia seems to 392 constitute an independent pattern of diversification from the rest of 393 the family with respect to environmental gradients and to have a 394 


\section{Discussion}

The angiosperm family Cunoniaceae has had strong associations 397 with both tropical and extratropical environments over its evolu- 398 tionary history (Fig. 2), yet tropical environments currently hold 399 many more species. Remarkably, this difference in diversity seems 400 to have arisen within the last 12 Myr (Fig. 3), suggesting higher 401 recent diversification in the tropics relative to the extratropics. We 402 also find significantly less phylogenetic diversity in tropical regions 403 than expected given their species richness $(i$. e. significant phyloge- 404 netic clustering; Fig. 4, Table 2), suggesting that recent radiations 405 have greatly increased the number of species in the tropics without 406 substantially increasing phylogenetic diversity.

The tropical radiations that comprise the majority of Cunon- 408 iaceae species may have arisen from extatropical ancestors. If so, this 409 would belie the general angiosperm pattern of species-poor extrat- 410 ropical lineages descending from tropical ancestors [9]. Rather, it 411 would suggest that that extratropics have been an important provider ${ }_{412}$ of diversity in tropical regions. However, the frequent switching of ${ }_{413}$ Cunoniaceae lineages between the extratropics and tropics limits 414 our ability to reconstruct ancestral environmental preferences of lin- 415 eages (Fig. 2), at least from distribution data for extant taxa. The ${ }_{416}$ fossil record indicates that the family Cunoniaceae first appeared 417 during the Late Cretaceous in Antarctica ( 70 Ma, [60]. During this ${ }_{418}$ time, Antarctica supported a highly diverse vegetation, dominated 419 by Podocarpites and Nothofagus [61], which is similar in taxonomic 420 composition to today's Valdivian rainforest in Chile ([48]; and refer- ${ }_{421}$ ences therein). Although there are no climatic models which suggest 422 whether Antarctica experienced freezing or non-freezing conditions ${ }_{423}$ 
$70 \mathrm{Ma}$, the compositional similarity with extant Valdivian forests, 424 which do experience freezing, suggests that the ancestor of present- 425 day Cunoniaceae lineages originated in an environment with freezing 426 temperatures.

Based on distribution data from extant taxa, a tropical 428 or extratropical origin for the most speciose genus in the family, 429 Weinmannia is also not clear (Fig. 2). A morphological and molecular 430 cladistic analysis shows that Weinmannia section Leiospermum, from 431 extratropical New Zealand, tropical New Caledonia, and other islands 432 from the South Pacific, is the sister taxon to the remainder of the ${ }_{433}$ genus [62]. These tropical and extratropical affiliations in the basal 434 section of Weinmannia could indicate an origin of the clade associated 435 with the interface between freezing and non-freezing environments. 436 Meanwhile, in section Weinmannia, the most recently derived section 437 of the genus, species from the tropical Mascarene islands are the ${ }_{438}$ sister clade of the American species [62]. The American species of ${ }_{439}$ section Weinmannia represent an impressive radiation that coincides 440 with the Andean uplift ( $\sim 60$ species in the Andes from Argentina ${ }_{441}$ to Mexico). Following our ecological classification of species, the 442 section Weinmannia is represented by only one extratropical species ${ }_{443}$ (in southern South America), yet those species distributed across the ${ }_{444}$ "Tropical Andes" are not inhabiting truly tropical environments (Fig. 445 1, Table 2). Rather, they occur at the interface between freezing 446 and non-freezing temperatures in mid and high elevations, which is 447 why so many of them are classified as generalists. Meanwhile, the ${ }_{448}$ fossil record shows a potential ancestor of section Weinmannia in 449 the extratropical Tasmania [63]. Therefore, an extratropical origin 450 is distinctly possible for the hyperdiverse genus Weinmannia as a ${ }^{451}$ whole and the recently radiated section Weinmannia. 
history of Cunoniaceae. For example, across angiosperms as a whole, 455 a pattern of decreasing hydraulic conduit diameter with increasing 456 latitude is thought to be an adaptive consequence of lineages mov- 457 ing into freezing environments [5, 64]. Evidence for this pattern in 458 Weinmannia [65] could be taken to suggest a tropical origin for this ${ }_{459}$ genus, with a later dispersal into freezing environments. However, 460 phylogenetic evidence suggests an extratropical origin for Weinman- 461 nia is as probable as a tropical origin (Fig. 2). We therefore suggest 462 that varying conduit diameter among species may just as likely rep- 463 resent either a plastic response to the presence or absence of freezing 464 conditions or an adaptive trend of increasing conduit diameter when 465 lineages move into tropical environments from extratropical ones. 466 The latter pattern in vessel diameter is evident in Nothofagus, a 467 genus whose extratropical origin is more certain. Nothofagus species 468 inhabiting tropical environments are only found in New Guinea and 469 have larger vessel diameters than the remaining species of the genus, 470 which inhabit extratropical environments [66]. These patterns in 471 Cunoniaceae and Nothofagus suggest that extratropical biota can 472 potentially change their hydraulic architecture when dispersing into 473 tropical, non-freezing environments.

Beyond the origin of Cunoniaceae and its most species-rich $\quad 475$ genus, the diversification history of the family shows two time periods 476 during which tropical lineages became more numerous than extrat- 477 ropical lineages, beginning $\sim 47$ and $\sim 12 \mathrm{Ma}$ (Fig. 3). The start of 478 the first time period is synchronous with the early Eocene Climatic 479 Optimum [67], which is the warmest period of the Cenozoic and may 480 have spurred lineage diversification in the tropics. This warm period 481 ended $\sim 30$ Myr before present, corresponding with the inception of 482 Antarctic freezing around the Eocene-Oligocene boundary [67]. This 483 freezing is linked with the extinction of the Antarctic flora, including 484 Cunoniaceae present there $[68,69]$. The second time period dur- 485 
ing which tropical lineages gained predominance started in the late 486

Miocene (after $12 \mathrm{Myr}$ ). During this later time period, global temper- ${ }_{487}$ atures continued to cool, culminating in the Pleistocene glaciations. 488

At this time the southern extratropical regions of the world would $\quad 489$

have been subject to important environmental changes, including 490

increased seasonality and dryness in southern mid-latitudes, which 491

may have caused a large number of extinctions [70]. Such extinctions 492

could explain the discrepancy in diversification rate between the 493

tropics and extratropics over the last $12 \mathrm{Myr}$. It is important to keep 494

in mind however, that these differences in lineage diversity over the 495

evolutionary history of Cunoniaceae are inferred from phylogenetic 496

data on extant lineages. The actual lineage diversity of Cunoniaceae 497

in extratropical or tropical regions of the world during past geological 498

epochs may well have been higher, with some lineages not surviving 499

$\begin{array}{ll}\text { until the present day. } & 500\end{array}$

The negative relationship between species richness (SR) and 501 standardized phylogenetic diversity (SPD) observed across environ- 502 mental bins (Fig. 4) suggests that the environmental peak of SR 503 in the Cunoniaceae family is explained by radiation of a subset of 504 lineages into new environments. Similar reasoning has been applied 505 to other systems. On one hand, phylogenetic clustering (i. e. low 506 SPD) in Floridan plant communities has been interpreted as a conse- 507 quence of habitat filtering for a subset of lineages containing specific, 508 phylogenetically conserved ecological traits [71]. On the other hand, 509 evidence for phylogenetic clustering in the western Cape flora of 510 South Africa has been discussed as a function of multiple, rapid 511 radiations $[72,73]$. Indeed, differences in the mean number of species 512 per genus for genera inhabiting the tropics versus the extratropics 513 in Cunoniaceae reinforce the hypothesis of restricted radiation for 514 a largely tropical subset of lineages. While the tropics house 215515 species from 21 genera (10.2 spp per genus on average), the extrat- 516 
ropics house 47 species from 16 genera (2.9 spp per genus on average) 517 (Table 2). In other words, the relatively few species inhabiting the 518 extratropics come from a roughly similar number of genera as the 519 many species in the tropics.

Higher species richness in the tropics can arise from multiple, 521 non-mutually exclusive mechanisms, such as area effects, time for 522 speciation, stronger biotic interactions or increased mutation rates 523 (reviewed by [74]). In the case of Cunoniaceae, area effects do not 524 seem a feasible explanation because its truly tropical distribution is 525 restricted to Australasia and Madagascar, a much narrower distri- 526 bution than the combined generalist and extratropical distribution $\quad 527$ of the family (Fig. 1). An explanation based on time for speciation 528 also seems unlikely, because this would imply a later dispersion of 529 Cunoniaceae into freezing environments and, as we have shown here, 530 an extratropical origin for the family seems as likely (Fig. 2), or per- 531 haps more likely considering the fossil record, than a tropical origin. 532 Furthermore, tropical species are more phylogenetically clustered 533 than extratropical species, which suggests that a tropical distribution 534 may be novel for the family compared to an extratropical distribution. 535 Instead, high tropical species richness in Cunoniaceae may be due 536 to high recent diversification rates in tropical Cunoniaceae lineages, 537 which could in turn be due to a multiplicity of processes including 538 stronger biotic interactions within tropical lineages (e. g. [75]) or in- 539 creased mutation rates linked to higher temperature [76]. Regardless, 540 future studies are clearly needed to address the mechanisms behind ${ }_{541}$ the radiation of Cunoniaceae into non-freezing environments. 542

The prominent radiation of Weinmannia in the Andean 543 mountains is not easily reconciled with environmental factors gener- 544 ally considered to increase speciation rate. An historical perspective 545 may work better. The Andes are not older than the South American 546 extratropics, yet they are much more diverse ( $\sim 60$ vs. 1 spp of ${ }_{547}$ 
bioRxiv preprint doi: https://doi.org/10.1101/2020.01.23.916817; this version posted January 24, 2020. The copyright holder for this preprint (which was not certified by peer review) i available under aCC-BY-ND 4.0 International itcense.

Higher mutation rates due to increased temperatures and/or solar 549 radiation are also not feasible, because Weinmannia prefers relatively ${ }_{550}$ colder and cloudy environments in the Andes [78]. An explanation 551 for the radiation based on competition does not represent a strong 552 hypothesis either, since Weinmannia is a pioneer genus and a weak ${ }_{553}$ competitor [79]. In contrast, the high taxonomic diversity in low ${ }_{554}$ latitudes of the Andes may be associated mainly with topographic 555 dynamism during the relatively recent Andean uplift [80, 81].

Our findings present an explanation for Southern Hemi- 557 sphere biogeographic trends which goes beyond the traditional 558 dispersal-vicariance dichotomy by explicitly focusing on the 559 environmental context under which lineages evolved. The family 560 Cunoniaceae is of clear importance, in terms of diversity and abun- 561 dance, in both tropical and extratropical regions. As such it serves 562 as a model family for understanding the nature of shifts between ${ }_{563}$ tropical and extratropical environments, and their consequence for 564 diversification. In contrast to the general pattern in angiosperm 565 biogeography $[9,5]$, we find that Cunoniaceae lineages have made 566 frequent shifts between tropical and extratropical environments. 567 Further, while the general narrative for biogeography in angiosperms is one of tropical-origin lineages spreading into the extratropics [8], the New Caledonian and Indonesian radiation of Cunoniaceae and 570 the radiation of Weinmannia in the tropical Andes, may represent 571 exceptions to this rule. These radiations seem to have extratropical 572 origins or at least to come from lineages that have continually existed 573 at the extratropical-tropical interface. Therefore, the dispersal of 574 Cunoniaceae lineages into tropical biomes represents a striking 575 case of non-tropical biota contributing taxonomic and evolutionary 576 diversity to tropical biodiversity hotspots. 
CONICYT PIA APOYO CCTE AFB170008. R.A.S. is supported by a Newton International Fellowship from The Royal Society and by Conicyt PFCHA/Postdoctorado Becas Chile/2017 N³140189. A.R.G. is supported by a NERC studentship (NE/L002558/1). K.G.D. was supported by a Leverhulme International Academic Fellowship during the time this research was completed.

\section{References}

[1] Robert F Thorne. Classification and geography of the flowering plants. The botanical review, 58(3):225327, 1992.

[2] Elgene O Box. Plant functional types and climate at the global scale. Journal of Vegetation Science, 7(3):309-320, 1996.

[3] Walter S Judd, Roger W Sanders, and Michael J Donoghue. Angiosperm family pairs: preliminary phylogenetic analyses. Harvard papers in Botany, pages 1-51, 1994.

[4] Robert E Ricklefs and Susanne S Renner. Species richness within families of flowering plants. Evolution, 48(5):1619-1636, 1994.

[5] Amy E Zanne, David C Tank, William K Cornwell, Jonathan M Eastman, Stephen A Smith, Richard G FitzJohn, Daniel J McGlinn, Brian C O'Meara, Angela T Moles, Peter B Reich, et al. Three keys to the radiation of angiosperms into freezing environments. Nature, 506(7486):89, 2014.

[6] Michael J Donoghue. A phylogenetic perspective on the distribution of plant diversity. Proceedings of the National Academy of Sciences, 105(Supplement 1):11549-11555, 2008.

[7] Ricardo A Segovia, Toby Pennington, Tim Baker, Fernanda Coelho De Souza, Danilo Neves, Charles C Davis, Juan J Armesto, Ary Olivera-Filho, and Kyle Dexter. Freezing and water availability structure the evolutionary diversity of trees across the americas. BioRxiv, page 728717, 2019.

[8] John J Wiens and Michael J Donoghue. Historical biogeography, ecology and species richness. Trends in ecology \& evolution, 19(12):639-644, 2004.

[9] Andrew J Kerkhoff, Pamela E Moriarty, and Michael D Weiser. The latitudinal species richness gradient in new world woody angiosperms is consistent with the tropical conservatism hypothesis. Proceedings of the National Academy of Sciences, 111(22):8125-8130, 2014.

[10] Elizabeth L Spriggs, Wendy L Clement, Patrick W Sweeney, Santiago Madriñán, Erika J Edwards, and Michael J Donoghue. Temperate radiations and dying embers of a tropical past: the diversification of $<$ i $>$ viburnum $</$ i $>$. New Phytologist, 207:340-354, 2015.

[11] Richard W Barnes, Robert S Hill, and Jason C Bradford. The history of cunoniaceae in australia from macrofossil evidence. Australian Journal of Botany, 49(3):301-320, 2001. 
bioRxiv preprint doi: https://doi.org/10.1101/2020.01.23.916817; this version posted January 24, 2020. The copyright holder for this preprint

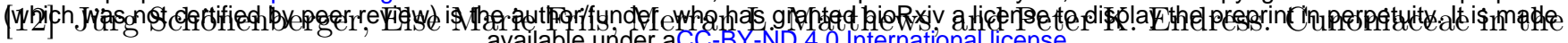
cretaceous of europe: Evidence from fossil flowers. Annals of Botany, 88(3):423 - 437, 2001.

[13] Jason C Bradford and Richard W. Barnes. Phylogenetics and classification of cunoniaceae (oxalidales) using chloroplast dna sequences and morphology. Systematic Botany, 26(2):354 - 385 - 32, 2001.

[14] Peter H Raven and Daniel I Axelrod. Angiosperm biogeography and past continental movements. Annals of the Missouri Botanical Garden, 61(3):539-673, 1974.

[15] GE Wilford and PJ Brown. Maps of late mesozoic-cenozoic gondwana break-up: some palaeogeographical implications. History of the Australian vegetation: Cretaceous to Recent, pages 5-13, 1994.

[16] Peter H Weston and Robert S Hill. Southern (austral) ecosystems. 2013.

[17] Peter Wilf, N Rubén Cúneo, Ignacio H Escapa, Diego Pol, and Michael O Woodburne. Splendid and seldom isolated: the paleobiogeography of patagonia. Annual Review of Earth and Planetary Sciences, 41, 2013.

[18] Vanessa C Bowman, Jane E Francis, Rosemary A Askin, James B Riding, and Graeme T Swindles. Latest cretaceous-earliest paleogene vegetation and climate change at the high southern latitudes: palynological evidence from seymour island, antarctic peninsula. Palaeogeography, Palaeoclimatology, Palaeoecology, 408:26-47, 2014.

[19] Richard C. Winkworth, Steven J. Wagstaff, David Glenny, and Peter J. Lockhart. Plant dispersal n.e.w.s from new zealand. Trends in Ecology Evolution, 17(11):514 - 520, 2002.

[20] Jesus Munoz, Angel M Felicisimo, Francisco Cabezas, Ana R Burgaz, and Isabel Martinez. Wind as a long-distance dispersal vehicle in the southern hemisphere. Science, 304(5674):1144-1147, 2004.

[21] Isabel Sanmartin, Livia Wanntorp, and Richard C Winkworth. West wind drift revisited: testing for directional dispersal in the southern hemisphere using event-based tree fitting. Journal of Biogeography, 34(3):398-416, 2007.

[22] Michael D Crisp, Mary TK Arroyo, Lyn G Cook, Maria A Gandolfo, Gregory J Jordan, Matt S McGlone, Peter H Weston, Mark Westoby, Peter Wilf, and H Peter Linder. Phylogenetic biome conservatism on a global scale. Nature, 458(7239):754, 2009.

[23] Edeline Gagnon, Jens J Ringelberg, Anne Bruneau, Gwilym P Lewis, and Colin E Hughes. Global succulent biome phylogenetic conservatism across the pantropical caesalpinia group (leguminosae). New Phytologist, 222(4):1994-2008, 2019.

[24] Isabel SanMartin and Fredrik Ronquist. Southern hemisphere biogeography inferred by event-based models: plant versus animal patterns. Systematic biology, 53(2), 2004.

[25] Carlos Jaramillo and Andrés Cárdenas. Global warming and neotropical rainforests: a historical perspective. Annu. Rev. Earth Planet. Sci., 41:741-766, 2013.

[26] Dolph Schluter, Trevor Price, Arne Ø Mooers, and Donald Ludwig. Likelihood of ancestor states in adaptive radiation. Evolution, 51(6):1699-1711, 1997.

[27] Mark Pagel. The Maximum Likelihood Approach to Reconstructing Ancestral Character States of Discrete Characters on Phylogenies. Systematic Biology, 48(3):612-622, 071999. 
bioRxiv preprint doi: https://doi.org/10.1101/2020.01.23.916817; this version posted January 24, 2020. The copyright holder for this preprint

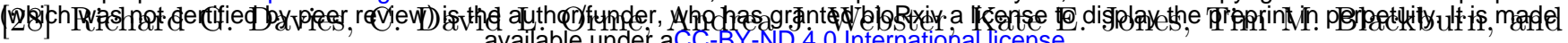
Kevin J. Gaston. Environmental predictors of global parrot (aves: Psittaciformes) species richness and phylogenetic diversity. Global Ecology and Biogeography, 16(2):220-233, 2007.

[29] W Daniel Kissling, Wolf L Eiserhardt, William J Baker, Finn Borchsenius, Thomas LP Couvreur, Henrik Balslev, and Jens-Christian Svenning. Cenozoic imprints on the phylogenetic structure of palm species assemblages worldwide. Proceedings of the National Academy of Sciences, 109(19):7379-7384, 2012 .

[30] Euridice N Honorio Coronado, Kyle G Dexter, R Toby Pennington, Jérôme Chave, Simon L Lewis, Miguel N Alexiades, Esteban Alvarez, Atila Alves de Oliveira, Iêda L Amaral, Alejandro AraujoMurakami, et al. Phylogenetic diversity of amazonian tree communities. Diversity and Distributions, 21(11):1295-1307, 2015.

[31] Vanessa L Rezende, Kyle G Dexter, R Toby Pennington, and Ary T Oliveira-Filho. Geographical variation in the evolutionary diversity of tree communities across southern south america. Journal of biogeography, 44(10):2365-2375, 2017.

[32] Marten Winter, Vincent Devictor, and Oliver Schweiger. Phylogenetic diversity and nature conservation: where are we? Trends in ecology $\&$ evolution, 28(4):199-204, 2013.

[33] Marcel Cardillo. Phylogenetic structure of mammal assemblages at large geographical scales: linking phylogenetic community ecology with macroecology. Philosophical Transactions of the Royal Society B: Biological Sciences, 366(1577):2545-2553, 2011.

[34] Caroline M. Tucker and Marc W. Cadotte. Unifying measures of biodiversity: understanding when richness and phylogenetic diversity should be congruent. Diversity and Distributions, 19(7):845-854, 2013.

[35] Scott A Chamberlain and Carl Boettiger. R python, and ruby clients for gbif species occurrence data. Technical report, PeerJ Preprints, 2017.

[36] R Core Team et al. R: A language and environment for statistical computing. 2013.

[37] Alexander Zizka, Daniele Silvestro, Tobias Andermann, Josué Azevedo, Camila Duarte Ritter, Daniel Edler, Harith Farooq, Andrei Herdean, María Ariza, Ruud Scharn, et al. Coordinatecleaner: Standardized cleaning of occurrence records from biological collection databases. Methods in Ecology and Evolution, 10(5):744-751, 2019.

[38] Robert J Hijmans, Susan E Cameron, Juan L Parra, Peter G Jones, and Andy Jarvis. Very high resolution interpolated climate surfaces for global land areas. International Journal of Climatology: A Journal of the Royal Meteorological Society, 25(15):1965-1978, 2005.

[39] Arthur D Chapman. Principles of data quality. GBIF, 2005.

[40] Josep M Serra-Diaz, Brian J Enquist, Brian Maitner, Cory Merow, and Jens-C Svenning. Big data of tree species distributions: how big and how good? Forest Ecosystems, 4(1):30, 2017.

[41] Kenneth J Feeley and James T Stroud. Where on earth are the "tropics"? Frontiers in Biogeography, 10(1-2), 2018.

[42] IPDJ Harris, Philip D Jones, Timothy J Osborn, and David H Lister. Updated high-resolution grids of monthly climatic observations-the cru ts3. 10 dataset. International journal of climatology, 34(3):623$642,2014$. 
bioRxiv preprint doi: https://doi.org/10.1101/2020.01.23.916817; this version posted January 24, 2020. The copyright holder for this preprint

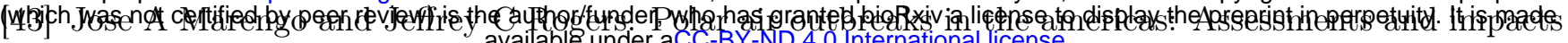
during modern and past climates. In Interhemispheric climate linkages, pages 31-51. Elsevier, 2001.

[44] Stephen A Smith and Joseph F Walker. Py phlawd: A python tool for phylogenetic dataset construction. Methods in Ecology and Evolution, 10(1):104-108, 2019.

[45] Kazutaka Katoh and Daron M Standley. Mafft multiple sequence alignment software version 7: improvements in performance and usability. Molecular biology and evolution, 30(4):772-780, 2013.

[46] Alexandros Stamatakis. Raxml version 8: a tool for phylogenetic analysis and post-analysis of large phylogenies. Bioinformatics, 30(9):1312-1313, 2014.

[47] Stephen A Smith and Brian C O'Meara. treepl: divergence time estimation using penalized likelihood for large phylogenies. Bioinformatics, 28(20):2689-2690, 2012.

[48] Imogen Poole, Alberta MW Mennega, and David J Cantrill. Valdivian ecosystems in the late cretaceous and early tertiary of antarctica: further evidence from myrtaceous and eucryphiaceous fossil wood. Review of Palaeobotany and Palynology, 124(1-2):9-27, 2003.

[49] Patrick W Sweeney, Jason C Bradford, and Porter P Lowry. Phylogenetic position of the new caledonian endemic genus hooglandia (cunoniaceae) as determined by maximum parsimony analysis of chloroplast dna. Annals of the Missouri Botanical Garden, pages 266-274, 2004.

[50] Daniel P Faith. Conservation evaluation and phylogenetic diversity. Biological conservation, 61(1):110, 1992.

[51] Kyle G Dexter, Ricardo A Segovia, and Andy R Griffiths. Exploring the concept of lineage diversity across north american forests. Forests, 10(6):520, 2019.

[52] Susanne A Fritz and Andy Purvis. Selectivity in mammalian extinction risk and threat types: a new measure of phylogenetic signal strength in binary traits. Conservation Biology, 24(4):1042-1051, 2010.

[53] Constantinos Tsirogiannis and Brody Sandel. Phylomeasures: a package for computing phylogenetic biodiversity measures and their statistical moments. Ecography, 39(7):709-714, 2016.

[54] Brody Sandel. Richness-dependence of phylogenetic diversity indices. Ecography, 41(5):837-844, 2018.

[55] LJ Harmon, JT Weir, CD Brock, RE Glor, and W Challenger. Geiger: investigating evolutionary radiations. Bioinformatics, 24:129-131, 2008.

[56] E. Paradis and K. Schliep. ape 5.0: an environment for modern phylogenetics and evolutionary analyses in R. Bioinformatics, 35:526-528, 2018.

[57] David Orme, Rob Freckleton, Gavin Thomas, Thomas Petzoldt, Susanne Fritz, Nick Isaac, and Will Pearse. caper: Comparative Analyses of Phylogenetics and Evolution in R, 2018. R package version 1.0.1.

[58] Steven W Kembel, Peter D Cowan, Matthew R Helmus, William K Cornwell, Helene Morlon, David D Ackerly, Simon P Blomberg, and Campbell O Webb. Picante: R tools for integrating phylogenies and ecology. Bioinformatics, 26(11):1463-1464, 2010.

[59] Mark P. Robertson, Vernon Visser, and Cang Hui. Biogeo: an $\mathrm{r}$ package for assessing and improving data quality of occurrence record datasets. Ecography, 39(4):394-401, 2016. 
bioRxiv preprint doi: https://doi.org/10.1101/2020.01.23.916817; this version posted January 24, 2020. The copyright holder for this preprint

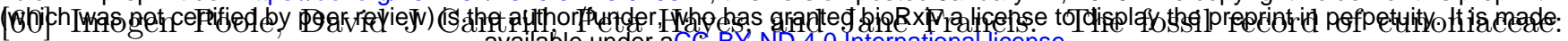
new evidence from late cretaceous wood of antarctica? Review of Palaeobotany and Palynology, 111(1-2):127-144, 2000.

[61] Imogen Poole, David Cantrill, and Torsten Utescher. A multi-proxy approach to determine antarctic terrestrial palaeoclimate during the late cretaceous and early tertiary. Palaeogeography, Palaeoclimatology, Palaeoecology, 222(1-2):95-121, 2005.

[62] Jason C Bradford. A cladistic analysis of species groups in weinmannia (cunoniaceae) based on morphology and inflorescence architecture. Annals of the Missouri Botanical Garden, pages 565-593, 1998.

[63] RJ Carpenter and AM Buchanan. Oligocene leaves, fruit and flowers of the cunoniaceae from cethana, tasmania. Australian Systematic Botany, 6(2):91-109, 1993.

[64] Amy E Zanne, William D Pearse, William K Cornwell, Daniel J McGlinn, Ian J Wright, and Josef C Uyeda. Functional biogeography of angiosperms: life at the extremes. New Phytol., 218(4):1697-1709, 2018.

[65] William C Dickison. Wood anatomy of weinmannia (cunoniaceae). Bulletin of the Torrey Botanical Club, pages 12-23, 1977.

[66] HE Dadswell and HD Ingle. The wood anatomy of new guinea nothofagus b1. Australian journal of botany, 2(2):141-153, 1954.

[67] James Zachos, Mark Pagani, Lisa Sloan, Ellen Thomas, and Katharina Billups. Trends, rhythms, and aberrations in global climate 65 ma to present. Science, 292(5517):686-693, 2001.

[68] JE Francis. Antarctic palaeobotany: clues to climate change. 1996.

[69] EM Truswell and MK Macphail. Polar forests on the edge of extinction: what does the fossil spore and pollen evidence from east antarctica say? Australian Systematic Botany, 22(2):57-106, 2009.

[70] Dallas C Mildenhall. New zealand late cretaceous and cenozoic plant biogeography: a contribution. Palaeogeography, palaeoclimatology, palaeoecology, 31:197-233, 1980.

[71] Jeannine Cavender-Bares, Adrienne Keen, and Brianna Miles. Phylogenetic structure of floridian plant communities depends on taxonomic and spatial scale. Ecology, 87(sp7):S109-S122, 2006.

[72] Félix Forest, Richard Grenyer, Mathieu Rouget, T Jonathan Davies, Richard M Cowling, Daniel P Faith, Andrew Balmford, John C Manning, Şerban Procheş, Michelle van der Bank, et al. Preserving the evolutionary potential of floras in biodiversity hotspots. Nature, 445(7129):757, 2007.

[73] G Anthony Verboom, Jenny K Archibald, Freek T Bakker, Dirk U Bellstedt, Ferozah Conrad, Leanne L Dreyer, Félix Forest, Chloé Galley, Peter Goldblatt, Jack F Henning, et al. Origin and diversification of the greater cape flora: ancient species repository, hot-bed of recent radiation, or both? Molecular Phylogenetics and Evolution, 51(1):44-53, 2009.

[74] Gary G. Mittelbach, Douglas W. Schemske, Howard V. Cornell, Andrew P. Allen, Jonathan M. Brown, Mark B. Bush, Susan P. Harrison, Allen H. Hurlbert, Nancy Knowlton, Harilaos A. Lessios, Christy M. McCain, Amy R. McCune, Lucinda A. McDade, Mark A. McPeek, Thomas J. Near, Trevor D. Price, Robert E. Ricklefs, Kaustuv Roy, Dov F. Sax, Dolph Schluter, James M. Sobel, and Michael Turelli. Evolution and the latitudinal diversity gradient: speciation, extinction and biogeography. Ecology Letters, 10(4):315-331, 2007. 
bioRxiv preprint doi: https://doi.org/10.1101/2020.01.23.916817; this version posted January 24, 2020. The copyright holder for this preprint ( Foundations of tropical forest biology, pages 163-173, 2002.

[76] Andrew P Allen, James F Gillooly, Van M Savage, and James H Brown. Kinetic effects of temperature on rates of genetic divergence and speciation. Proceedings of the National Academy of Sciences, 103(24):9130-9135, 2006.

[77] KM Gregory-Wodzicki. Uplift history of the Central and Northern Andes: A review. Geological society of america bulletin, 112(7):1091-1105, JUL 2000.

[78] J Homeier, FA Werner, SR Gradstein, S Breckle, and M Richter. Potential vegetation and floristic composition of andean forests in south ecuador, with a focus on the rbsf. Ecological Studies, 198:87, 2008.

[79] Christopher H Lusk. Long-lived light-demanding emergents in southern temperate forests: the case of weinmannia trichosperma (cunoniaceae) in chile. Plant Ecology, 140(1):111-115, 1999.

[80] Alexandre Antonelli, Johan AA Nylander, Claes Persson, and Isabel Sanmartin. Tracing the impact of the andean uplift on neotropical plant evolution. Proceedings of the National Academy of Sciences, 106(24):9749-9754, 2009.

[81] Thiago F Rangel, Neil R Edwards, Philip B Holden, José Alexandre F Diniz-Filho, William D Gosling, Marco Túlio P Coelho, Fernanda AS Cassemiro, Carsten Rahbek, and Robert K Colwell. Modeling the ecology and evolution of biodiversity: biogeographical cradles, museums, and graves. Science, 361(6399):eaar5452, 2018. 